\title{
UMA ANÁLISE DOS REFLEXOS NAS RELAÇÕES \\ TRABALHISTAS DA LEI N. 12.984 DE 2/6/2014 QUE \\ CRIMINALIZA A DISCRIMINAÇÃO DOS PORTADORES DO \\ VÍRUS HIV E DOS DOENTES DE AIDS
}

Maria Aparecida Alkimin

Pós-doutora em Democracia e Direitos Humanos pela Universidade de Coimbra/ Ius Gentium Conimbrigae, Doutora e Mestre em Direito pela Pontifícia Universidade Católica de São Paulo, Professora do Programa de Mestrado em Direito do Centro Universitário Salesiano de São Paulo, professora do Curso de Direito do Centro Universitário Salesiano de São Paulo e membro do conselho editorial da Revista Direito \& Paz.

Ana Maria Viola de Sousa

Pós-doutora em Democracia e Direitos Humanos pela Universidade de Coimbra/ lus Gentium Conimbrigae (2013); Doutora em Direito das Relações Sociais pela Pontifícia Universidade Católica de São Paulo (2003); Mestre em Direito pela Universidade Pontifícia Católica de São Paulo (1998). Atualmente Professora e Pesquisadora do Programa de Mestrado em Direito pelo Centro Universitário Salesiano de São Paulo; Professora e Pesquisadora do curso de Direito pela Universidade do Vale do Paraíba (UNIVAP) e Universidade Paulista (UNIP). Integra o corpo de cooperação técnico, científico e cultural, compondo a Cátedra da UNESCO de Juventude, Educação e Sociedade, com sede na Universidade Católica de Brasília.

\section{Resumo}

Desde o seu surgimento, a AIDS se tornou uma das grandes causas de discriminação do trabalhador no ambiente laboral e, sem uma tutela específica, mas apenas genérica, intensifica a vulnerabilidade do trabalhador portador dessa doença. No Brasil, no âmbito trabalhista, não há norma específica na tutela jurídica dos portadores de AIDS/HIV, valendo-se de orientaçôes emanadas pela Constituição Federal e da Lei 9.029/95 para a defesa desses trabalhadores. A edição da Lei 12.984/14, objetiva tornar crime, qualquer forma de discriminação contra a pessoa em razão de condição de portador do vírus ou doente de AIDS. No presente trabalho, faz-se uma análise nos reflexos que o crime de discriminação previsto nesta lei possa repercutir na seara do Direito do Trabalho. Demonstra-se que a aplicaçáo é bastante promissora, pois o texto abrange tanto a relação de trabalho quanto relação de emprego, inclusive relação de vínculo estatutário. Procurou a 
lei proteger o trabalhador no meio ambiente de trabalho, defendendo o respeito à dignidade da pessoa humana e a consideração às condiçóes físicas do portador do vírus e da doença. Com a presente lei, é indiscutível o avanço legislativo brasileiro, punindo com multa e prisão qualquer ato direto ou indireto de discriminação às pessoas em razão de sua condição de portador da doença. Mas ainda fica o desafio de torna-la visível e efetiva a sua aplicabilidade.

\section{Palavras-chave}

Igualdade; Crime de discriminação; Relaçôes trabalhistas; Lei 12.984/14.

\section{Resumen}

Desde su surgimiento, la SIDA se hizo una de las grandes causas de discriminación del trabajador en el ambiente laboral y, sin una tutela específica, pero sólo genérica, intensifica la vulnerabilidad del trabajador portador de esa enfermedad. En Brasil, en el ámbito laboral, no hay norma específica en la tutela jurídica de los portadores de SIDA/VIH, valiéndose de orientaciones emanadas por la Constitución Federal y de la Ley 9.029/95 para la defensa de esos trabajadores. La edición de la Ley 12.984/14, objetiva hacer crimen, cualquier forma de discriminación contra la persona en razón de condición de portador del virus o enfermo de SIDA. En el presente trabajo, se hace un análisis en los reflejos que el crimen de discriminación previsto en esta ley pueda repercutir en la seara del Derecho del Trabajo. Se demuestra que la aplicación es bastante promissora, pues el texto comprende tanto la relación de trabajo cuánto relación de empleo, inclusive relación de vínculo estatutario. Buscó la ley proteger el trabajador enmedio ambiente de trabajo, defendiendo el respeto a la dignidad de la persona humana y la consideración a las condiciones físicas del portador del virus y de la enfermedad. Con la presente ley, es indiscutível el avance legislativo brasileño, puniendo con multa y prisión cualquiera ato directo o indirecto de discriminación a las personas en razón de su condición de portador de la enfermedad. Pero aún queda el desafío de la haces visible y realiza su aplicabilidade.

\section{Palabras clave}

Igualdad; Crimen de discriminación; Relaciones laborales; Ley 12.984/2014.

\section{Introdução}

A igualdade e a não discriminação são princípios basilares constitucionais devendo ser observado em todas as searas da vida. $\mathrm{Na}$ área trabalhista, mais ainda, pois o que se objetiva na escolha do candidato ao emprego é a sua avaliação tendo como critérios 
fatores objetivos que afiram sua aptidáo para a vaga pretendida. Ademais, o simples fato de a pessoa ser portadora do vírus HIV ou estar doente de AIDS não retira sua aptidão ao trabalho.

Embora na esfera trabalhista não haja uma lei específica que tutele os direitos do trabalhador acometido pelo HIV/AIDS, é certo que a discriminação é vedada, apesar de genericamente tratado na Constituição Federal, na Consolidação das Leis do Trabalho, bem assim na Lei 9.029/95 que veda práticas discriminatórias por diversos motivos.

Ainda são diversas as situaçóes em que o soropositivo é discriminado, em razão da cultura do preconceito acerca da AIDS. Quando uma pessoa comum é discriminada no trabalho, há ofensa à sua dignidade, mas se a pessoa discriminada o é, por sua situação de saúde, é duplamente desrespeitada, não só em sua dignidade de pessoa, como também como trabalhadora. Combatendo essa situaçáo foi promulgada em 2 de junho de 2014, a Lei 12.984, que criminaliza a discriminação contra pessoas portadoras do HIV/AIDS.

Embora essa Lei seja de natureza penal, já que constitui crimina atos de discriminação, retrata também a efetivação da tutela com reflexos no ambiente laboral. Esse é o objetivo do presente artigo. Discute-se aqui os principais reflexos trabalhistas da Lei antidiscriminatória, analisando, principalmente, o âmbito de sua aplicabilidade, o enfoque do bem jurídico ofendido e o alcance das condutas discriminatórias tipificadas.

A análise ora apresentada possui grande relevância no ambiente laboral, uma vez que a legislação em comento, ao criminalizar condutas discriminatórias, procura conservar, preservar e defender a garantia dos direitos humanos, a liberdade e igualdade como princípios e valores inerentes à pessoa humana, proporcionando, cada vez mais, condiçóes decentes de trabalho.

\section{O Princípio da Igualdade e a Não-Discriminação}

\subsection{Igualdade e Dignidade}

A dignidade é atributo natural inerente à pessoa humana, cuja pessoa humana representa uma unidade corporal e espiritual, dotada de razão e liberdade. A igualdade é um direito natural proclamado pela DUDH (1948) nos seguintes termos: "Todas as pessoas nascem livres e iguais em dignidade e direitos. São dotadas de razão e consciência e devem agir em relaçáo umas às outras com espírito de solidariedade." (Artigo I, DUDH, 1948)

Tratam-se de princípios-valores inerentes à condição humana, logo, dignidade humana e igualdade se completam e se complementam, ou seja, um homem só tem dignidade se recebe tratamento igual aos seus semelhantes, pois entre semelhantes não pode haver diferenças de tratamento. 
Toda pessoa humana representa uma unidade espiritual e moral, da qual erradia a dignidade humana, cuja dignidade é um atributo inerente a toda pessoa humana, que a torna igual em relação a todos os seus semelhantes, haja vista que todos os seres humanos são dotados de razão e autodeterminação e como integrantes do meio natural possuem direitos naturais compatíveis com a existência humana, tais como a vida, liberdade, igualdade, direitos esses inarredáveis da condição humana.

Nas palavras de Fábio Konder Comparato:

(...)o ser humano passar a ser considerado, em sua igualdade essencial, como ser dotado de liberdade e razão, não obstante as múltiplas diferenças de sexo, raça, religiáo ou costumes sociais. Lançavam-se, assim, os fundamentos intelectuais para a compreensão da pessoa humana e para a afirmação da existência de direitos universais, porque a ela inerentes. (COMPARATO, 2003, p. 11)

A universalização dos direitos humanos, nascida após a 2a ${ }^{\text {a }}$ Grande Guerra, com a proclamação dos Direitos Humanos pela ONU, conscientizando que a pessoa é meio e náo fim em si mesmo, portanto, exigindo por parte do Estado que representa poder e soberania a tutela aos chamados direitos de primeira geraçáo, os quais impóem ao Estado um dever positivo e negativo, traduzindo-se no dever de proteger, promover e defender e na omissão ou inércia de provar lesão, ou seja, um facere e um non facere.

Nesse sentido o Estado Democrático de Direito exaltou como princípio-valor fundamento da ordem jurídica a dignidade da pessoa humana (rodapé; art. 1º. III, CF), donde irradiou a positivação de direitos fundamentais ligados à dignidade da pessoa humana, que saíram do plano do direito natural, para incorporar o direito posto, pois somente se materializa e concretiza a dignidade humana quando o Estado tutela o direito à vida e o exercício à vida livre e igual.

A igualdade enquanto extensão da dignidade da pessoa humana, embora de conteúdo principiológico, também possui conteúdo normativo que compóe a ordem jurídica na qualidade de direito fundamental de todo cidadão: Art. 5․, caput da CF: "Todos são iguais perante a lei, sem distinção de qualquer natureza, garantindo-se aos brasileiros e aos estrangeiros residentes no País, a inviolabilidade do direito à vida, à liberdade, à igualdade, à segurança e à propriedade, nos termos....”

Depreende-se que a igualdade é um valor do Estado democrático de Direito, e, nesse sentido, a proteção a direitos humanos, positivados e incorporados na ordem constitucional sob o manto dos direitos fundamentais que garantem condiçóes dignas de vida é uma exigência do Estado do Bem-Estar Social. Dessa forma, não se pode falar em dignidade humana, sem a tutela por parte do Estado da vida, saúde, igualdade e liberdade, atributos naturais inerentes ao simples existir da pessoa humana. 
Nas palavras de Canotilho:

(...) o princípio da igualdade não é apenas um princípio de Estado de Direito, mas também um princípio de Estado Social. Independentemente do problema da distinção entre igualdade fática e igualdade jurídica e dos problemas econômicos e políticos ligados à primeira...o princípio da igualdade sob o ponto de vista jurídico-constitucional assume relevo enquanto princípio de igualdade de oportunidades. (Equality of opportunities) e de condiçóes reais de vida. (2010, p. 567)

Por outro lado, pode-se afirmar que a igualdade não é um princípio absoluto, pois a igualdade implica tratar diferentemente os desiguais, ou seja, a diferença de tratamento é um mecanismo que busca tratar os iguais de forma igual e os desiguais de forma desigual, levando-se em conta que há diferenças naturais entre os seres humanos.

Nesse sentido, surgiu a necessidade de tratamento diferente à minorias, no sentido de se buscar estabelecer uma igualdade formal para classes ou grupos, naturalmente, em condição de desigualdade, como é o caso da criança, do idoso, do consumidor, do trabalhador e do deficiente.

Logo, impóem-se medidas legislativas e açóes afirmativas no sentido de buscar não apenas um favorecimento, mas antes de tudo uma igualdade formal de minorias socialmente inferiorizadas, buscando a eficácia real da igualdade e da dignidade humana. Nesse, sentido, pode-se afirmar que a pessoa portadora do vírus HIV ou doente de AIDS integra a classe da minoria, impondo-se, consequentemente, um tratamento específico no afã de se coibir a discriminação.

\subsection{Igualdade no Direito do Trabalho e a Não-Discriminação}

A igualdade, conforme visto, apresenta conteúdo e princípios ligados ao direito natural, contudo foi positivada sob a forma de direito fundamental, assumindo um conteúdo normativo, razão pela qual, de acordo com a primeira dimensão dos Direitos Humanos, impóe ao Estado o dever de prestação, notadamente por meio de regras de não- discriminação; cujas regras obrigam os particulares, pois regras de efetivação de direitos e garantias fundamentais são oponíveis contra todos.

De acordo com o art. $3^{\circ}$., IV da CF/88: "Constituem objetivos fundamentais da República Federativa do Brasil: “(...)....IV - promover o bem de todos, sem preconceitos de origem, raça, sexo, cor, idade e quaisquer outras formas de discriminação."

O conteúdo normativo do princípio da igualdade, que impóe ao Estado açóes, medidas, políticas públicas antidiscriminatórias, tem razão de existir mais intensa no âmbito das relaçóes de trabalho, onde a desigualdade real e material (socioeconômica) entre 
patrão e empregado é histórica e insuperável, demonstrando que jamais haverá igualdade real entre as partes no contrato de trabalho.

Sob essa ótica, pondera-se que a igualdade de tratamento nas relações de trabalho constitui-se em direito fundamental e social do trabalhador, protegido pela ordem jurídica constitucional que veda a discriminação salarial, no exercício de função e de critério de admissão por motivo de sexo, idade, cor ou estado civil (inciso XXX, art. 7o , CF); proibição de qualquer discriminação no tocante a salário e critério de admissão do trabalhador portador de deficiência (inciso XXXI, art. 7º., da CF); proibição de distinção de trabalho manual, técnico e intelectual ou entre os profissionais respectivos (inciso XXXII, art. $7^{\circ}$. da CF).

Como bem assevera Emmanuel Teófilo Furtado, “o princípio da isonomia, dentre outros, tem por fito assegurar a garantia individual de igualdade e, noutro passo, coibir protecionismo, preteriçôes impertinentes ou favoritismos." (2004, p. 141)

Pode-se afirma que do princípio da igualdade decorre a vertente negativa que é o princípio da não-discriminação, permitindo a todo trabalhador acesso ao trabalho em condiçôes de igualdade. Nesse sentido, impóe um comportamento negativo e positivo por parte do empregador, ou seja, positivo no sentido de criação de deveres de tratamento no ambiente de trabalho, e negativo no sentido de que é vedado ao empregador distinguir um trabalhador ou um grupo de trabalhadores por determinadas circunstâncias.

Dessa forma, a igualdade de tratamento, em matéria trabalhista, importa na igualdade de acesso à oportunidade de emprego e ao pleno emprego. $\mathrm{O}$ art. $170 \mathrm{da} \mathrm{CF}$ estabelece que um dos princípios da ordem econômica no Brasil é a busca pelo pleno emprego, logo, requer por parte dos empregadores comportamentos positivo e negativo acima referidos.

Por outro lado, comporta relativizar o princípio da igualdade e da náo-discriminação em matéria de igualdade de oportunidades, ressaltando que igualdade perante a lei (isonomia) significa que todos são iguais em direitos e garantias condizentes a uma vida digna na sociedade, o que veda a discriminação injustificada, contudo, objetivamente considerando, há desigualdades reais e circunstanciais entre os homens, inclusive, entre trabalhadores no que se refere às aptidóes, qualificação e qualidade de trabalho, condição física para determinada atividade etc., o que torna elementar o estabelecimento de diferenciaçóes que não se confundem com ato arbitrário e discriminatório, portanto, desigualdades naturais poderão implicar tratamento diferenciado no sentido de igualar os iguais e desigualar os desiguais, possibilitando a inclusão no mercado de trabalho através da discriminação positiva.

John Rawls, em importante estudo comparativo conclui que:

(...) as imerecidas desigualdades requerem uma compensação e, desde que as desigualdades de nascimento e dons naturais são imerecidas, terão de 
ser de algum modo compensadas. Assim, o princípio afirma que, visando tratar igualmente todas as pessoas e proporcionar uma autêntica igualdade de oportunidades, a sociedade terá de conceder maior atenção aos que tiverem menos dons naturais e aos que nascerem em posiçôes sociais menos favorecidas. A ideia é compensar as desvantagens rumo à igualdade. (RAWLS, 1981, p. 96, apud MARTINS, 2008, p. 92)

Náo basta proclamar a igualdade e generalizá-la, a desigualdade jurídica existe e deve ser promovida pelo próprio Estado e particulares visando justificar o tratamento diferenciado a pessoas que se encontrem em situação de inferioridade, carência ou de escassez de proteçáo que conduza à igualdade de oportunidades dentro do critério da razoabilidade, através de uma discriminação positiva-inclusiva.

No âmbito das relaçóes de trabalho, a discriminação ocorre quando o empregador, sem qualquer motivação ou razão plausível, trata empregados ou pretensos empregados, de forma diferenciada, logo, a discriminação pode ocorrer tanto durante a execução do contrato de trabalho como também na fase pré-contratual e, ainda, após a extinção da relação empregatícia (fase pós-contratual).

A Organização Internacional do Trabalho (OIT), através da Convenção n. 111 proíbe a discriminação em matéria de emprego e ocupação, definindo discriminação no artigo 1․ como: "toda distinção, exclusão ou preferência fundada na raça, cor, sexo, religião, opiniáo política, ascendência nacional ou origem social, que tenha por efeito destruir ou alterar a igualdade de oportunidade ou de oportunidade em matéria de emprego ou de profissão.”

Essa Convenção da OIT veda a discriminação de forma genérica, não especificou nenhum tipo de situação, logo, visa proibir a discriminação de todas as formas e por qualquer razão.

No âmbito interno, além de a CF garantir como direito fundamental a igualdade (art. $5^{\circ}$. e art. $7^{\circ}$ ) e náo-discriminação, a Lei n. 9029 de 13/4/95 em seu artigo primeiro proíbe a adoção de qualquer prática discriminatória e limitativa para efeito de acesso à relação de emprego, ou sua manutenção, por motivo de sexo, origem, raça, cor, estado civil, situação familiar ou idade.

\section{Discriminação do Trabalhador Portador do Vírus HIV/AIDS}

O trabalho dignifica o homem quando realizado em condiçóes decentes e, principalmente, com igualdade de condiçóes e imune a toda e qualquer forma de discriminação. No mundo do trabalho há diversas formas de discriminaçáo contra a pessoa do trabalhador, ou seja, por raça, cor, opção sexual, religiosa etc., mas a que macula a imagem e a alma do trabalhador que já padece do sofrimento físico e psíquico em razão de portar algum tipo de doença é, justamente, a discriminação por motivo de doença. 
A saúde é um bem jurídico imaterial que compóe a personalidade de toda pessoa, sendo certo que como direito e garantia fundamental está tutelado pelo legislador constituinte, cuja positivação impóe ao Estado o dever de proteção, preservação e prevenção. (art. 196, CF). Nesse sentido, o Estado tutela o meio ambiente laboral visando zelar e preservar a saúde física e psíquica do trabalhador, adotando açóes e medidas para combater e prevenir doenças ocupacionais ou do trabalho.

$\mathrm{O}$ trabalhador adoecido, em regra, tende a se tornar menos produtivo, não ficando imune a algum tipo de discriminação, contudo, a doença que mais discrimina e que é considerada estigmatizante e de isolamento social do trabalhador, pouco importando a sua produtividade, é a AIDS.

Trata-se de um mal que também leva à discriminação, segregação e isolamento do portador do vírus HIV ou da doença de AIDS, notadamente, no ambiente de trabalho, causando o dano ou sofrimento secundário no trabalhador que já padece de um sofrimento contínuo em razão da doença e de sua evolução.

O trabalhador portador do vírus HIV ou doente de AIDS tem seu sofrimento redobrado ou até mesmo fortalecido em razão da discriminação no ambiente de trabalho, afetando a dignidade não apenas enquanto pessoa humana, como também enquanto trabalhador, haja vista que deprecia o ambiente de trabalho, compromete a empregabilidade e até mesmo a qualidade de vida no trabalho, em suma, dificulta ou impede a consecução do trabalho decente e do desenvolvimento sustentável, vilipendiando valores inerentes à personalidade do trabalhador, dentre eles, a dignidade da pessoa humana.

A AIDS, ou seja, a Síndrome da Imunodeficiência Adquirida através do vírus HIV (Vírus da Imunodeficiência Adquirida-SIDA) danifica o sistema imunológico humano, resultando dos estágios avançados da infecção pelo HIV infecçôes oportunistas ou neoplasias relacionadas com o HIV.

Desde o seu surgimento, por volta do início da década de 80, a AIDS se tornou uma das grandes causas de discriminação do trabalhador no ambiente de trabalho, e certo que, sem tutela específica, apenas genérica, intensificando, dessa feita, a vulnerabilidade do trabalhador portador da doença, gerando medo de perder o emprego ou de padecer sofrimento no ambiente de trabalho em razão da discriminação, e, em muitos casos, por falta de conhecimento ou informação acerca da doença. Conforme já se asseverou noutra passagem:

É fato público e notório a discriminação sofrida o ambiente de trabalho pelo empregado vitimado pela AIDS, pois há desinformação ou informaçôes desencontradas que atribuem ao aidético o status de "grande mal” para o meio social e profissional em que vive, justamente porque há desinformação sobre essa doença que somente é transmissível pelas vias sanguíneas e sexual. (ALKIMIN, 2009, p. 125) 
Durante muitos anos, a AIDS/HIV no ambiente de trabalho não era considerada uma forma de discriminação nas relações de trabalho de fácil solução, notadamente diante da ocorrência da rescisão contratual unilateral por parte do empregador.

No Brasil, no âmbito trabalhista, não há norma específica e com tutela jurídica específica de proteção ao trabalhador portador da AIDS/HIV, mas há normas gerais que regulam as repercussóes da AIDS/HIV nas relaçóes de trabalho, dentre elas, o art. $3^{\circ}$. e seu inciso IV da CF, que estabelece princípios orientadores da ordem jurídica constitucional e infraconstitucional, como norma aberta que é, estabeleceu como objetivo fundamental da República Federativa do Brasil a promoção do bem de todos, sem preconceitos de origem, raça, sexo, cor, idade e "qualquer forma de discriminação", com vistas à proteção, defesa e promoção da dignidade da pessoa humana (art. 1º, III,CF).

A Lei n. 9029/95 que veda a prática discriminatória no que tange ao acesso ao trabalho e à sua manutenção por motivo de sexo, origem, raça, cor, estado civil, situação familiar ou idade, omitiu a discriminação por doença, inclusive HIV/AIDS, o que gerou grande celeuma nos pretórios trabalhistas a despeito da possibilidade de reintegração do trabalhador portador do vírus HIV ou aidético, demitido unilateralmente pelo empregador, cuja celeuma foi resolvida com a invocação do princípio que se sobrepóe a todas as normas e princípios, qual seja, a dignidade de pessoa e o acesso ao emprego e a sua preservação sem discriminação.

Em 2012 o direito de reintegração do trabalhador portador do vírus HIV ou doente de AIDS deixou de ser questão controvertida e se impôs segurança jurídica com a edição da Súmula 443 do TST, segundo a qual se presume abusiva e discriminatória a demissáo do empregado portador de doença grave, dentre elas a AIDS/HIV, garantindo-se-lhe o direito à reintegração.

$\mathrm{Na}$ verdade, o direito do trabalhador de não ser discriminado por motivo de AIDS/ HIV, é um direito e uma garantia fundamental, que constitui extensão da dignidade da pessoa humana e também o direito de ter a sua privacidade e intimidade resguardada, logo, constitui grave violação ao direito da personalidade do trabalho a discriminação por motivo de AIDS.

No âmbito internacional, a Convenção n. 111 da OIT, que entrou em vigor em 1958, ratificada pelo Brasil em 1965, de conteúdo aberto e genérico, passou a vedar no plano internacional a discriminação no acesso à informação profissional, à admissão no emprego e às condições de trabalho por motivo de raça, cor, sexo, religião, opinião política, ascendência nacional ou origem social, além de "qualquer outra exclusão que tenha por efeito anular ou alterar a igualdade de tratamento no emprego", comportando, dessa forma, interpretação extensiva para abranger o trabalhador doente, inclusive, portador do HIV/AIDS. 
No âmbito internacional, ainda, em termos de proteção específica ao trabalhador portador do HIV ou doente de AIDS, em 1988 foi editada a Declaração Conjunta da OMS/OIT que estabeleceu princípios e medidas de proteção ao trabalhador portador do HIV/AIDS, dentre as medidas protetivas, ficou deliberado: a) proibição de detectação do HIV/AIDS no ato da contratação ou da prévia contratação; b) confidencialidade sobre toda informação médica do trabalhador; c) dispensa de qualquer informação obrigatória por parte do trabalhador sobre a situação do HIV/AIDS; d) proteção ao trabalhador afetado ou suspeito de HIV/AIDS no ambiente de trabalho de toda estigmatização ou discriminação por parte dos colegas, empregador etc.

No Brasil, em termos de proteção específica ao empregado portador de HIV/AIDS, o Conselho Federal de Medicina, em atenção às diretivas da OMS/OIT, editou a Resolução n. 1359/92, que prevê a confidencialidade e privacidade do estado clínico ou de saúde do trabalhador portador de HIV/AIDS, estabelecendo que os médicos da empresa estão proibidos de revelarem ao empregador o diagnóstico do empregado ou candidato ao emprego, somente lhes sendo permitido informar se o empregado está ou não capacitado para o exercício da função almejada; devendo, contudo, informar ao sistema de saúde a existência de moléstia infecto-contagiosa, garantindo o anonimato do paciente.

Importante pontuar que tanto a Declaração conjunta OMS/OIT, como a Resolução n. 1359/92 veda ao médico revelar ao empregador o diagnóstico do empregado ou do candidato ao emprego, sob pena de revelação de segredo profissional, que constitui crime capitulado no art. 154 do Código Penal.

O exame médico, nos termos do artigo 168 da CLT, deve ser realizado tanto no ato da contratação como no ato da saída do emprego, contudo, tais exames estão limitados à verificação da capacidade física e mental do trabalhador.

Emmanuel Teófilo Furtado entende que havendo riscos de contaminação por parte de terceiros, seria legítima a exigência do exame de HIV/AIDS:

Diante da evidência científica do risco de transmissão do HIV no ambiente de labor, imperiosa se torna a proteção de clientes e dos demais empregados, devendo ser adotados critérios que estabeleçam as circunstâncias que impóe a investigação a respeito da condição de portador do vírus HIV de algum empregado ou candidato a emprego, posto que, sedo soropositivo, para aquela atividade específica, por conta do mais expressivo perigo de transmissão, não terá o trabalhador a qualificação exigida para o emprego. (2004, p. 247)

Deve-se ponderar esse posicionamento, haja vista que o teste ou testes devem ser rigorosamente voluntários e livres de qualquer coerção, e os programas de diagnóstico devem respeitar as diretrizes internacionais sobre sigilo, orientação e consentimento. Inclusive, os resultados dos testes de HIV devem ser confidenciais e não prejudicar o acesso 
a empregos, a manutenção de empregos, a garantia de emprego e as oportunidades de promoção. (Recomendação n. 200 da OIT). Deve-se, na verdade, empreender medidas educativas e esclarecedoras ao trabalhador ou candidato à vaga no emprego, a fim de assumam a condição de portador do HIV e realizem os testes voluntários. Caso haja submissão ao teste voluntário, certamente esse trabalhador, caso o resultado seja positivo, não poderá ser discriminado, mas adaptado à função compatível com sua situação clínica, não podendo, obviamente, colocar em risco a saúde e integridade de terceiros.

Em 2010 (2 de junho) na Conferência Geral da Organização Internacional do Trabalho, em Genebra, foi editada a Recomendação n. 200 sobre "o HIV e a AIDS e o mundo do trabalho", com o objetivo de tutelar os direitos humanos e fundamentais dos trabalhadores portadores da doença em questão e visando a promoção de açóes de prevenção e assistência no local de trabalho, além de estabelecer diretrizes para o enfrentamento do estigma e da discriminação no ambiente laboral, visando a proteção à dignidade humana, liberdades fundamentais, igualdade e personalidade do trabalhador.

O Brasil, visando implementar as diretrizes da Recomendação n. 200 da OIT de 2010 e visando proteger o trabalhador discriminado por motivo de AIDS/HIV, inovou no posicionamento jurisprudencial com a edição da Súmula 443, anteriormente referida, e mais recentemente estabeleceu a tutela penal ao trabalhador vitimado pela discriminação por motivo de HIV/AIDS, não apenas no ambiente laboral, como também educacional, tendo sido editada, em 2/6/2014, a Lei n. 12.984 que "define o crime de discriminação dos portadores do vírus da imunodeficiência humana (HIV) e doentes de aids, estabelecendo, dessa forma, tipificação penal e criminalização para a discriminação do aidético no ambiente de trabalho.

\section{Proteção Jurídica Contra a Discriminação do Trabalhador Portador do Ví- rus HIV/AIDS}

A DUDH, como tratado de direitos humanos que dispóe de normas que buscam tutelar a dignidade da pessoa humana, a liberdade e a igualdade, é o primeiro instrumento de proteção contra a discriminação do trabalhador portador do vírus HIV ou do doente de AIDS. A DUDH universalizou o direito-valor-regra à igualdade dispondo que: "Todos são iguais perante a lei e têm direito, sem qualquer distinção a igual proteção da lei. Todos têm direito a igual proteção contra qualquer discriminação que viole a presente Declaração e contra qualquer incitamento a tal discriminação.” (art. 7o.)

A Constituição da República Federativa do Brasil incorporou os direitos humanos disciplinados pela DUDH, inserindo-os na ordem jurídica sob o manto dos direitos e garantias fundamentais e, consequentemente, primando pela integralização do Estado Democrático de Direito, estabeleceu princípios gerais e específicos para salvaguarda da 
dignidade da pessoa humana, fundamento primário, vedando expressamente a discriminação, dispondo que um dos objetivos fundamentais da República Brasileira para construção de uma sociedade livre, justa e solidária é combater o preconceito e toda forma de discriminação (art. 30.,IV,CF/88), e continua dispondo no art. 5. Que "todos são iguais perante a lei, sem distinção de qualquer natureza."

Portanto, a igualdade, tal como a dignidade da pessoa humana, é valor fundamento do Estado Democrático de Direito, sendo vedada toda e qualquer forma de discriminaçáo que interfira no acesso ou na permanência do trabalhador no mercado de trabalho, seja como empregado ou como prestador de serviços ou, ainda, trabalhador do setor público, sociedade de economia mista etc.

A discriminação do trabalhador portador do vírus do HIV ou do doente de AIDS encontra proteção jurídica não apenas nos princípios que norteiam as relaçóes sociais e trabalhistas e que estão inseridos na ordem jurídica constitucional, como também encontra proteção jurídica no âmbito trabalhista, cível e penal, conforme será abordado adiante.

\subsection{Proteção Trabalhista e Previdenciária}

$\mathrm{Na}$ esfera trabalhista, não há lei específica que regule expressamente a discriminação do trabalhador portador do vírus HIV ou doente de AIDS, conforme discorrido, a vedação da discriminação nas relações de trabalho é ampla e genericamente tratada pela CF, pela CLT em algumas hipóteses, dentre elas, relacionadas ao trabalho da mulher, à questão salarial, etc., sendo certo que não há expressa menção ao trabalhador portador de HIV/AIDS.

A discriminação em caso de HIV/AIDS sempre foi tratada à luz do princípio da dignidade humana e da não-discriminação, referidos na $\mathrm{CF}$, e à luz da aplicação extensiva e sistemática da Lei n. 9029/95, que embora vede de forma específica a prática de condutas discriminatórias contra a mulher, admite de forma ampla a sua aplicação em relação a outras hipóteses de discriminação, quais sejam, "por motivo de sexo, origem, raça, cor, estado civil, situação familiar ou idade" (art. $1^{\circ}$.), portanto, não há que se falar em taxatividade do rol que motiva a discriminação nas relaçôes de trabalho; sendo certo que o legislador disse menos do que pretendia dizer, contudo, o objetivo da lei foi vedar qualquer forma de discriminação, pois deve ser perquirido o fim social e integrativo da norma.

Segundo Rubens Limongi de França, em relação ao trabalho e bem-estar:

(...) além da obrigação social do homem, o trabalho é objeto de um direito inalienável do ser humano, indispensável à auto-realização em todos os setores de sua complexidade. Não pode assim o aidético ser discriminado na admissão e no exercício da atividade produtiva a não ser que, em razão do tipo de trabalho e do estágio da moléstia, não haja possibilidade técnica 
de impedir o risco de contágio. Do mesmo modo, não pode a AIDS ser considerada causa jurídica da despedida do empregado. (1990, p. 18/19).

A ausência de regulação da matéria, tendo-se em vista que o empregado portador do vírus HIV ou doente de AIDS não ser contemplado por lei com a garantia provisória no emprego, gerou durante muito tempo divergência na Jurisprudência trabalhista brasileira, haja vista que não era absoluto o entendimento que o fato de ser portador do vírus HIV/ doente de AIDS produzida ou não a presunçáo favorável ao trabalhador no sentido de se tratar de dispensa discriminatória. Nesse sentido, não tendo o empregador o conhecimento prévio ou náo tendo o trabalhador prova de que era do conhecimento prévio do empregador, a despedida seria considerada regular, diante do legítimo exercício do direito potestativo do empregador.

Segundo Alice Monteiro de Barros, a Lei 9029/95 não previu expressamente a hipótese "estado de saúde", caso o fizesse não haveria dificuldade de interpretação e aplicação no caso de HIV/AIDS, contudo, "não se pode aplicar a Lei n. 9029/95 aos portadores do HIV, uma vez que ela contém preceito de natureza penal insuscetível de interpretação analógica e extensiva."(2001, p. 276)

Independentemente da aplicação ou não da Lei 9029/95 para coibir a discriminação no trabalho por motivo de HIV/AIDS, o tratamento jurídico aplicado à matéria sempre esteve assentado nos princípios basilares da dignidade da pessoa humana, da isonomia e da não-discriminação, cuja tutela tem fundamento das normas e diretivas internacionais, dentre elas a Convenção n. 111 da OIT que, em linhas gerais, é de conteúdo aberto, pois além de vedar a discriminação em razão de raça, cor, sexo, religião, opinião pública, origem, permite aos países ratificantes incluírem outras formas de vedação da discriminação.

Dessa forma, a corrente que sempre prevaleceu nos tribunais trabalhistas era a da dispensa discriminatória presumida do empregado portador do HIV, quando não comprovado um motivo justificável, prevalecendo assim o princípio da isonomia e da dignidade da pessoa humana: "REINTEGRAÇÃO - EMPREGADO PORTADOR DO VÍRUS DA AIDS - Não obstante inexista no ordenamento jurídico lei que garanta a permanência no emprego do portador da Síndrome da Imunodeficiência Adquirida - AIDS, não se pode conceber que o empregador, munido do poder potestativo que lhe é conferido, possa despedir de forma arbitrária e discriminatória o empregado após tomar ciência de que este é portador do vírus HIV - Tal procedimento afronta o princípio fundamental da isonomia insculpido no caput do artigo quinto da Constituição Federal." (TST, nos ERR no 205359/1995, Ac. da SBDI 1, Rel. Min. Leonaldo Silva, in DJU de 14.05.1999, p. 43).

Buscando pacificar e estabelecer segurança jurídica, em 2012 o TST (Tribunal Superior do Trabalho) editou a Súmula 443 e buscou estabelecer uma segurança jurídica em relação da questão que envolve a demissão sem justa causa do empregado portador do vírus HIV ou doente de AIDS., estabelecendo a presunção em favor do trabalhador 
diante da dispensa por HIV/AIDS. Ressalta-se, entretanto, que essa Súmula tem natureza ampla, pois veda a dispensa discriminatória do empregado portador de doença grave, por estigma ou preconceito, admitindo-se a presunção da discriminação e garantindo o direito à reintegração do empregado.

Em relação à tipologia da discriminação do trabalhador por motivo de HIV/AIDS, deve-se analisar suas multifaces, ou seja:

\section{a) No curso do contrato de trabalho: com rescisáo contratual}

Considerando que a Súmula 443 não tem o condáo de disciplinar a forma da reintegração e os direitos decorrentes dessa reintegração, urge suprir a lacuna com o artigo 4º. Da lei n. 9029/95, cujo artigo dispóe que o rompimento do contrato por motivo discriminatório, faculta ao empregado optar: 1- pela readmissão com ressarcimento integral de todo o período do afastamento, mediante pagamento das remuneraçóes devidas, corrigidas monetariamente, acrescidas de juros legais; II- a percepção, em dobro, da remuneração do período de afastamento, corrigida monetariamente e acrescida dos juros legais.

Portanto, ocorrendo a rescisão do contrato de trabalho do empregado portador do vírus HIV ou doente de AIDS a presunção - juris tantum, pois admite-se prova em contrário- é de que houve a motivação discriminatória, podendo o empregado pleitear a reintegração ou readmissão com pagamento de todos os direitos atinentes ao período de afastamento ou o recebimento em dobro da remuneração ao período do afastamento corrigida por correção monetária e juros.

\section{b) No curso do contrato de trabalho: sem rescisáo contratual}

Nesse caso, a conduta discriminatória em relação ao trabalhador por motivo de HIV/AIDS viola a personalidade e a dignidade do trabalhador, tanto no aspecto pessoal como profissional, engendrando o assédio moral discriminatório, e, consequentemente violação do dever de respeito e consideração à pessoa do empregado.

Diante da violação dos deveres contratuais por parte do empregador ou de preposto seu a tutela jurídica trabalhista é a rescisão indireta do contrato de trabalho, donde decorrerá a indenização trabalhista, sem prejuízo da indenização de natureza civil; outrossim, sem prejuízo da aplicação da recente Lei 12.984/2014 que criminaliza a conduta discriminatória no ambiente de trabalho ou em relação ao trabalho.

Além disso, caberá a demissão por justa causa do preposto do empregador autor da conduta discriminatória e violadora da cláusula geral do dever de respeito e consideração ao próximo.

\section{c) Fases pré e pós- contratual}

$\mathrm{Na}$ fase pré-contratual a discriminação pode ocorrer quando o trabalhador portador do HIV ou doente de AIDS estiver no momento da entrevista, almejando vaga no emprego oferecido. Nesse caso, é vedada a invasão à intimidade e privacidade do empregado 
condicionando a admissão à vaga no caso de informaçôes ou testes relacionados ao estado de saúde do candidato à vaga.

Nesse sentido, Emmanuel Teófilo Furtado, referindo-se à Declaração da OMS/OIT anteriormente referida, afirma que " não se deve exigir a investigação do HIV/AIDS no ato da contratação do trabalhador, como etapa do processo seletivo, nem mesmo tendo o trabalhador obrigação de informar a respeito de sua situação relacionada com o HIV/ AIDS.” (2004, p. 239/240)

Nessa fase, considerando que não há formalização da relação de trabalho propriamente dita, não há que se falar em rescisão e indenização trabalhista, todavia, há consumação do dano moral e até mesmo material, em razão da perda da chance e quebra de expectativa de empregabilidade, o que não apenas intensifica o sofrimento moral, como também frustra a empregabilidade, gerando dano "in concreto".

No mesmo diapasão é a discriminação por motivo de HIV/AIDS após a rescisão contratual, através da divulgação ou propagação do estado de saúde do empregado portador do vírus HIV ou doente de AIDS, cabendo indenização na órbita do direito civil, com base na violação dos direitos da personalidade e da dignidade humana.

No âmbito previdenciário a primeira proteção surgiu com a Lei n. 7.670 de 1988, que concedida ao empregado doente e filiado ao RGPS a garantia de recebimento do auxílio-doença (comum) e a aposentadoria, além de garantir aludida Lei o direito do empregado de efetuar o saque dos valores depositados na conta vinculado do FGTS, cuja benefício também foi regulado pela Lei n. 8036/90.

Outrossim, o trabalhador portador do HIV/AIDS também tem assegurado o direito de receber tratamento médico, readaptação profissional, remédios (coquetéis etc.). $\mathrm{Na}$ Lei 8213/91, regulamentada pelo Decreto n. 3048/99 consta que independe de carência a concessão de auxílio-doença e aposentadoria no caso de o segurado estar acometido de AIDS (artigos 25, 151 da Lei n. 8213/91 e art. 30, III e 186, Dec. 3048/99).

Independentemente do caráter contributivo, o portador do vírus HIV e doente de AIDS também poderá pleitear o benefício social, denominado, LOAS (Lei n. 8.742/93, Lei Orgânica da Assistência Social) uma vez comprovada a carência e os requisitos da lei em referência, garantindo-lhe o piso de um salário mínimo nacional.

A lei do FGTS, Lei n. 8036/90, em seu artigo 20,XIII, estabelece que o trabalhador portador do vírus HIV, ou até mesmo se a doença acometer um de seus dependentes, tem direito de levantar os valores do FGTS depositados em conta vinculada, cujo levantamento abrange o saldo de todas as contas pertencentes ao trabalhador.

\subsection{Proteção Cível}

O trabalhador portador do vírus HIV ou doente de AIDS que sofre a discriminação, tanto na fase pré-contratual, como durante a execução do contrato de trabalho e após a 
extinção do contrato de trabalho, ou até mesmo sofre violação ao direito de privacidade e confidencialidade em relação ao seu estado de saúde, diante de eventual divulgação ou propagação do estado clínico ou resultado de exame, tem seus direitos da personalidade e a sua dignidade violados pelo empregador ou por preposto do empregador.

Não pairam dúvidas de que a conduta discriminatória dirigida contra o trabalhador acometido pela AIDS/HIV configura-se conduta contrária ao "dever preexistente" (PEREIRA, 2000, p. 50) de respeito à personalidade e dignidade de outrem, e, consequentemente, invade a seara do ato ilícito, ou seja, uma conduta (comissiva ou omissiva) praticada de forma voluntária e que viola a ordem jurídica posta, gerando o dano moral el ou material, cuja relação entre conduta e dano estão embasadas pelo nexo de causalidade, formando-se o tripé da responsabilidade civil: conduta-dano-nexo causal.

De acordo com o Código Civil, o ato ilícito se caracteriza como ação ou omissão voluntária, negligência ou imprudência que viole direito e cause dano a outrem, ainda que exclusivamente moral (art. 186), cuja prática de ato ilícito gera o dever de reparação (art. 927, CC).

Quando a conduta discriminatória por motivo de HIV/AIDS partir do empregador ou pretenso empregador, este responderá diretamente pela prática do ato ilícito, contudo, se a conduta discriminatória for praticada por preposto seu, a responsabilidade do empregador será objetiva, ou seja, o empregador ressarcirá o prejuízo moral/material da vítima da discriminação (art. 932, III, CC), podendo o empregador se valer da ação regressiva contra o agente causador do dano (art. 934, CC).

\subsection{Proteção Penal à Luz da Lei n. 12.984 de 2/6/2014, que Criminaliza a Discri- minação dos Portadores do Vírus HIV e doentes de AIDS}

A Lei n. 12984 que pune a discriminação do portador do vírus HIV ou doente de AIDS, tem dupla finalidade: a primeira regulamentar o art. 5․, XLI da CF/88, segundo o qual "a lei punirá qualquer discriminação atentatória dos direitos e liberdades fundamentais", e, dessa, forma busca criminalizar para atender a finalidade primordial que é, justamente, promover a inserção efetiva de soropositivos no ambiente escolar e do trabalho, podendo-se asseverar, inclusive, que no âmbito das relaçóes de trabalho, em razão de seu viés penal está agregada ao Código Penal para combater os crimes contra a organização do trabalho. A segunda finalidade é implementar as formas de proteção ao empregado portador do vírus HIV e doente de AIDS, grupo de minoria que merece proteção especial, conforme diretrizes traçadas pela Recomendação 200 da OIT (2010), no combate à discriminação e promoção da igualdade de oportunidade e de tratamento do portador do HIV e doente de AIDS. 
A Lei em comento, também retrata a efetivação do compromisso do governo brasileiro assumido diante da ratificação da Convenção sobre a Discriminaçáo no Emprego e na Ocupação (1958), baseando-se nos ditames dessa Convenção para prevenir e punir discriminação de trabalhador em condição real ou presumida de infecção de HIV.

A tutela penal com reflexos no meio ambiente laboral, visa, na verdade, conservar, preservar e prevenir a garantia dos direitos humanos, das liberdade fundamentais e igualdade de gênero como princípios e valores que são inerentes às relaçóes de trabalho e proporcionam condiçóes decentes de trabalho, tutelando a dignidade da pessoa humana.

Essa lei anti-discriminatória pune com reclusão de 1 a 4 anos, e multa, as condutas discriminatórias contra o portador do HIV e o doente de AIDS, em razáo da sua condição de portador ou de doente, tem como âmbito de aplicação a conduta discriminatória praticada em relação ao empregado no ambiente de trabalho ou ao pretenso candidato à ocupação de emprego ou trabalho, abrangendo também o trabalhador do setor público, assim como é punida a conduta discriminatória dirigida contra aluno em creche ou estabelecimento de ensino de qualquer curso ou grau, público ou privado. (art. $1^{\circ}$.)

Ipsis litteris, dispóe a Lei n. 12.984/2014:

Art. 1ํ Constitui crime punível com reclusão, de 1 (um) a 4 (quatro) anos, e multa, as seguintes condutas discriminatórias contra o portador do HIV e o doente de aids, em razáo da sua condição de portador ou de doente:

I - recusar, procrastinar, cancelar ou segregar a inscrição ou impedir que permaneça como aluno em creche ou estabelecimento de ensino de qualquer curso ou grau, público ou privado;

II - negar emprego ou trabalho;

III - exonerar ou demitir de seu cargo ou emprego;

IV - segregar no ambiente de trabalho ou escolar;

$\mathrm{V}$ - divulgar a condição do portador do HIV ou de doente de aids, com intuito de ofender-lhe a dignidade;

VI - recusar ou retardar atendimento de saúde.

No presente artigo, buscar-se-á o enfoque e reflexos trabalhista da referida Lei antidiscriminatória, ou seja, a negativa de emprego ou trabalho, a exoneração ou demissão do cargo ou do emprego, a segregação no ambiente de trabalho do portador do vírus HIV ou doente de AIDS, bem como a divulgação da condição de portador do vírus HIV ou doente de AIDS, com finalidade de ofender a dignidade do trabalhador, conforme disposto no art. $1^{\circ}$., incisos II, III, IV e V, da Lei n. 12.984/2014.

Importante se faz adotar uma interpretação literal e sistemática aos incisos acima referidos, a fim de se estabelecer o âmbito de aplicação da lei nas relaçóes de trabalho, o bem jurídico ofendido e os sujeitos envolvidos/afetados pela conduta discriminatória. 


\subsection{1. Âmbito de Aplicação}

Ao dispor o legislador no art. $1^{\circ}$., inciso I da Lei n. 12.984/2014 que caracteriza crime a conduta discriminatória contra o portador do HIV e o doente de AIDS, quando "negar emprego ou trabalho", certamente buscou abranger tanto a relação de emprego que se caracteriza, nos termos dos artigos $3^{\circ}$. e $2^{\circ}$. da CLT, como sendo a prestação de serviços de forma pessoal e continuada, subordinada e mediante recebimento de salário, abrangendo assim o empregado urbano, rural, doméstico, terceirizado, como também a relação de trabalho, que significa a prestação pessoal de serviços em troca de uma contraprestação financeira, abrangendo o autônomo, estagiário, voluntário, cooperado etc.

De acordo com o artigo 114 da CF (alterado pela EC n. 45/2004), a relação de trabalho é o fator de determinação da competência da Justiça do Trabalho, cuja relação de trabalho exclui a prestação de serviços consideradas como relações de consumo nos termos do Código de Defesa do Consumidor (Lei n. 8078/90), conforme posicionamento pacificado pelo STJ (Superior Tribunal de Justiça) através da Súmula 363.

De acordo com essa linha de raciocínio, todo e qualquer trabalhador que estiver inserido na organizaçáo produtiva e do trabalho que venha a ser vitimado pela discriminação em razão de portar o vírus HIV ou possuir o estado real ou presumido de doente de AIDS, estará protegido pela criminalização da conduta discriminatória. Outrossim, importante asseverar que, na fase do pré-contrato ou na promessa de contratação, através de entrevistas, inclusive, havendo a discriminação em relação ao portador do HIV ou doente de AIDS, também incidirá a aplicação da Lei n.. 12.984/2014, pois o tipo penal descreve a conduta omissiva "negar emprego ou trabalho", e certo que em razão da discriminação.

Portanto, estagiário, voluntário, temporário, avulso, cooperado, etc que vier a ser vitimado pela conduta discriminatória no ambiente em que está prestando seu labor, ou seja, entregando sua força de trabalho em troca de uma contraprestação, estará protegido pela Lei n. 12.984/2014, ou seja, poderá invocar a tutela jurídica de natureza cível e penal.

A aplicação da tutela penal através da Lei n. 12984/2014 aos trabalhadores de forma geral e não apenas ao empregado- este sendo o trabalhador em sentido restrito-, está em sintonia com a Recomendação n. 200 da OIT que dispóe sobre a proteção contra a discriminação no trabalho do trabalhador ou candidato a emprego portador do vírus $\mathrm{HIV}$ ou doente de AIDS.

Quanto ao âmbito de aplicação, ainda, vislumbra-se que a Lei n. 12.984/2014, aplica-se tanto no âmbito privado como no âmbito público, pois tendo o legislador penalista disposto que constitui crime punível com reclusão a conduta discriminatória praticada contra o portador do HIV ou doente de AIDS, quando "exonerar ou demitir de seu cargo ou emprego" (art. $1^{\circ}$., inciso III), conduz o intérprete e aplicador à conclusão de que tanto o empregador da iniciativa privada, como o ente público que admitir empregado 
público regido pela CLT ou admitir servidor ou funcionário público regido por estatuto próprio (regime jurídico único ou estatuto do funcionalismo público), estará sujeito ao âmbito de aplicação da Lei penal em referência.

Terminologicamente considerando, o empregador da iniciativa privada empregada e demite do emprego, ao passo que o Poder Público, através da administração pública direta, indireta, autárquica, fundacional ou sociedade de economia mista, demite o empregado quando o admite sob o regime celetista, contudo, exonera do cargo ou função quando admite o trabalhador (servidor/funcionário público) mediante regime jurídico único ou estatuto do funcionalismo público.

\subsubsection{Bem Jurídico Ofendido}

A discriminação do trabalhador por motivo de portar o vírus HIV ou de se encontrar no estado real ou presumido de AIDS, ofende bem jurídico inerente à dignidade humana, gerando desigualdade e exclusão, consequentemente, ofende a dignidade da pessoa humana, tanto enquanto trabalhador, como cidadão no exercício dos direitos sociais, civis e políticos. A dignidade da pessoa humana impóe ao Estado e ao particular o respeito aos direitos humanos, liberdades fundamentais e aos direitos da personalidade do cidadão, em qualquer estado ou condição em que se encontre.

Pode-se afirmar que a igualdade de tratamento e de oportunidade no emprego ou no trabalho é o bem jurídico que em primeira ordem é violado, além de irradiar essa violação a violação a outros bens jurídicos, como a personalidade e dignidade do trabalhador.

$\mathrm{Na}$ verdade, todos os trabalhadores têm direito e garantia fundamental à igualdade de tratamento e de oportunidades no que se refere ao emprego, trabalho, formação e promoçáo profissionais, bem como às condiçóes de trabalho, sendo certo que o tomador dos serviços do empregado/trabalhador ou do servidor/funcionário público não poderá praticar qualquer discriminação direta ou indireta por motivo de o candidato ou trabalhador ser portador do vírus HIV ou doente de AIDS,

Ao dispor o legislador penal no inciso $\mathrm{V}$ do art. $1^{\circ}$. da Lei 12.984 que constitui crime de discriminação "divulgar a condição do portador do HIV ou de doente de aids, com intuito de ofender-lhe a dignidade", certamente buscou preservar e tutelar o direito à intimidade do trabalhador ou do candidato ao trabalho, cujo direito à reserva da intimidade e da vida privada do trabalhador abrange tanto o acesso como a divulgação de aspectos atinentes à esfera íntima e pessoal do trabalhador, como é o caso do estado clínico ou de saúde.

O direito à intimidade é uma extensão do direito da personalidade, e, segundo Goffredo Telles Junior (2001, p. 297) a personalidade corresponde ao conjunto de 
características ou caracteres inerente a cada individuo, que o distingue de seus semelhantes e que permitem em primeiro lugar o seu reconhecimento como pessoa e depois "como uma certa e determinada pessoa".

Nesse sentido, o direito à intimidade do trabalhador é indisponível, impóe ao empregador o dever de observância e respeito, devendo de se abster em praticar conduta omissiva ou comissiva que viole esse direito e garantia fundamental ligado à personalidade, e, como tal, correspondente à extensão da dignidade humana do trabalhador.

\subsubsection{Condutas Discriminatórias Descritas pela Lei n. 12.984/2014}

Conforme redação dada pelo legislador penal ao artigo $1^{\circ}$., incisos II, III,IV e V da Lei n. 12.984/2014, a criminalização da conduta discriminatória se aplica tanto à conduta omissa, como comissiva, desde que visem discriminar e impedir o acesso igualitário ao emprego ou trabalho, ou discriminar para excluir, segregar ou denegrir o trabalhador portador do vírus HIV ou doente de AIDS.

\section{a) Negativa de emprego ou trabalho (art. $1^{\circ}$., inciso II)}

O inciso II do art. $1^{\circ}$. da Lei n. 12.984 prevê uma conduta criminosa omissiva "negar emprego ou trabalho." Essa conduta omissiva, via de regra, ocorre na fase pré-contratual, ou seja, na fase da entrevista, informaçôes prestadas por terceiros etc., contudo, deve-se asseverar que a fase pré-contratual produz efeitos jurídicos, haja vista que cria expectativa de direito, inibindo o acesso à oportunidade de emprego ou trabalho, diante da discriminação.

A negação em oferecer emprego ou trabalho equivale à discriminação do trabalhador portador do vírus HIV ou doente de AIDS no ato da contratação ou da entrevista para admissão no emprego ou no trabalho, haja vista, conforme ressaltado em outra passagem, a referida Lei se aplica à relação de trabalho em sentido amplo (estagiário, voluntário, avulso, cooperado etc).

$\mathrm{Na}$ verdade, nenhum trabalhador ou candidato a emprego ou trabalho pode ser privilegiado, beneficiado, prejudicado ou privado do direito de acesso ao emprego e à liberdade de trabalho por motivo de discriminação em razão do estado clínico ou de saúde.

Nesse sentido, todos os trabalhadores tem igualdade de direito no que se refere ao acesso ao empregado e ao mercado de trabalho, com igualdade de oportunidade e de tratamento, cuja igualdade de acesso abrange a igualdade de formação e promoção profissionais, além da igualdade das condiçóes de trabalho.

De acordo com a Recomendação n. 200 da OIT: "A condição real ou presumida de infecção por HIV não deve ser motivo de discriminação, impedindo a contratação, a 
permanência no emprego ou a busca de iguais oportunidades em consonância com os dispositivos da Convenção sobre a Discriminação no Emprego e na Profissão, 1958.”

O empregador ou pretenso tomador dos serviços do trabalhador deve respeitar a intimidade do empregado ou do trabalhador (abrangendo servidor ou funcionário público) e não deve exigir do trabalhador ou candidato ao emprego informaçóes relativas ao seu estado de saúde, salvo quando particulares exigências ligadas ao exercício da função exigir essas informaçóes, cuja necessidade deverá ser manifestada por escrito e fundamentada, devendo as informaçóes acerca do estado de saúde serem prestadas ao médico que só poderá comunicar ao empregador se o trabalhador está apto ou inapto para o trabalho, salvo autorização escrita pelo trabalhador, o médico justificará a inaptidão.

Outra questão intimamente relacionada à admissão no emprego ou no trabalho é a exigência de teste e exames médicos como condição para contratação e demissão do trabalhador. Nos termos da Recomendação n. 200 da OIT, os trabalhadores que "buscam emprego e os candidatos a emprego, não devem ser obrigados a submeter-se a testes ou a outras formas de controle de HIV.” Essa Recomendação também ressalta que “os testes devem ser rigorosamente voluntários e livres de qualquer coerçáo, e os programas de diagnóstico devem respeitar as diretrizes internacionais sobre sigilo, orientação e consentimento."

A bem da verdade, tanto na iniciativa privada como na contratação por ente público, não se pode exigir, para efeitos de admissáo ou permanência no emprego, a realização ou apresentação de testes ou exames médicos, de qualquer natureza, para comprovação das condiçôes físicas ou psíquicas, conforme anteriormente asseverado, salvo aqueles testes ou exames quando particulares exigências inerentes à função a ser exercida o exigir, devendo a solicitação ao trabalhador ou ao candidato ser formalizada e fundamentada; tratando-se, nesse caso, de discriminação positiva.

\section{b) Exoneração ou demissáo do cargo ou emprego (Artigo 1º, inciso III)}

Trata-se de uma conduta comissiva "exonerar ou demitir de seu cargo ou emprego" (art. $1^{\circ}$. Inciso III) o empregado ou trabalhador (abrangendo o servidor/funcionário público) em razão de ser portador do vírus HIV ou doente de AIDS.

A igualdade tratamento de tratamento e a não-discriminação , para efeito de aplicação da Lei penal em comento, refere-se não apenas ao acesso ao emprego ou trabalho, como também há criminalização da conduta discriminatória que gera a eliminação do trabalhador da organização do trabalho, gerando o desemprego por motivo de discriminação.

Obviamente o empregador tem o direito potestativo de demitir seu empregado, sem necessidade de exteriorizar as motivações, arcando com o pagamento das verbas rescisórias e indenizatórias pertinentes à rescisão sem justa causa. Contudo, se dissimular a rescisão 
sem justa causa com a clara intenção de rescindir o contrato de trabalho por motivo de discriminação, ou seja, com o dolo de praticar a conduta descrita no tipo penal, cometerá o ilícito penal previsto no art. $1^{\circ}$, inciso III da Lei n. 12.984/2014. O direito de extinguir unilateralmente o contrato de trabalho deve ser revestido de ilicitude e respeito à dignidade humana.

Quando a lei se refere a "exonerar ou demitir de seu cargo ou emprego", entende-se sua aplicabilidade também no âmbito da administração pública. Em termos conceituais, cargo público é o lugar dentro da organização funcional da administração pública que, ocupado por servidor público tem funções específicas e remuneração fixadas em lei (CARVALHO FILHO, 2009, p. 463).

É interessante observar que na administração pública as situaçôes de mescla de regimes jurídicos estatutário e trabalhista são comuns. O regime diz-se "Estatutário", quando as regras que regulam as relaçóes funcionais dos servidores estão previstas na lei denominada Estatuto, que, no caso da União, é a Lei 8.112/90¹. É nesta lei que, no artigo 2o define que servidor público é a pessoa legalmente investida em cargo público, aquele que tradicionalmente foi denominado "funcionário público". Já no regime trabalhista, as normas que regulam a relação jurídica entre o servidor e o Estado se encontram na Consolidação das Leis do Trabalho (CLT). Há assim uma pluralidade normativa, já que cada ente da federação tem sua própria lei, cada qual adotando um específico ou os dois regimes simultaneamente, denotando autonomia de cada pessoa federativa de um em relação aos demais (União, Estado, Distrito Federal, Municípios). Por essa razão, Di Pietro (2010, p. 519) comenta que diante da contratação de servidores sob o regime da legislação trabalhista, a expressão "emprego público" passou a ser utilizada paralelamente a "cargo público", ambos para designar uma unidade de atribuiçóes, distinguindo-se uma da outra pelo tipo de vínculo que liga o servidor ao Estado: o ocupante do "emprego público" em um vínculo contratual, sob a regência da CLT; enquanto o ocupante de "cargo público" tem vínculo estatutário, regido pelo Estatuto dos Funcionários.

Do mesmo modo, os termos demissão e exoneração são institutos que também provocam confusão em seu emprego técnico, já que ambos se identificam com atos de extinção de vínculos. Porém, necessário distingui-los, pois "demissão" é ato de caráter punitivo, representando uma penalidade aplicada ao servidor em razão de uma infração funcional grave; já a "exoneração" é a dispensa do servidor por interesse dele próprio ou da administração, não havendo qualquer conotação de sentido punitivo (CARVALHO FILHO, 2009, p. 497).

No que tange à proibição de demissão ou exoneração do trabalhador portador do vírus HIV ou doente de AIDS, dispóe a Recomendação n. 200 da OIT:

1 Texto da Lei 8.112/90 está disponível em www.planalto.gov.br Acesso em 15.maio.2015. 
Condição real ou presumida de infecção por HIV não deve ser causa de término de relação de trabalho. Ausência temporária ao trabalho pela necessidade de prestar assistência a terceiros ou por motivo de enfermidade, relacionados com com o HIV ou a Aids, deve ser tratada da mesma forma que as ausências por outras razōes de saúde, levando em conta a Convenção sobre o Término da Relação de Trabalho por Iniciativa do Empregador, 1982. Pessoas com doenças relacionadas ao HIV náo devem ser proibidas de continuar realizando seu trabalho, com adaptação razoável se necessário, pelo tempo em que a medicina as considere aptas para fazê-lo. Medidas para recolocar essas pessoas em trabalho razoavelmente adaptado a sua capacidade, para encontrar-lhes outro trabalho por meio de programa de formação ou para facilitar-lhes o retorno ao trabalho devem ser encorajadas, levando em conta os instrumentos pertinentes da Organização Internacional do Trabalho e das Naçôes Unidas.

No Brasil, o TST adotou a Súmula 443, anteriormente referida, para vedar, expressamente a demissão discriminatório do empregado portador do vírus HIV ou doente de AIDS, cuja Súmula referida, é mais abrangente, pois estabelece a garantia no empregado dos empregados acometidos de doença grave, dentre elas, enquadra-se a AIDS/HIV.

\section{c) Segregaçáo no ambiente de trabalho (art. $1^{\circ}$.,inciso IV)}

Ao tipificar como crime punível com reclusão de 1 a 4 anos a segregação do trabalhador no ambiente de trabalho por motivo de portar o vírus HIV ou encontrar-se doente de AIDS, o legislador buscou proteger o trabalhador no meio ambiente do trabalho, que lhe deve proporcionar respeito e consideração aos seus atributos pessoais, além de condiçóes físicas e psíquicas para o pleno exercício da liberdade de trabalho e com igualdade de tratamento e de acesso às oportunidades de formação, qualificação e promoção profissional, imune às agressóes psíquicas, como é o caso da discriminação por motivo de portar vírus HIV ou doença de AIDS.

Constitui assédio discriminatório dirigido a candidato a emprego ou trabalho ou a trabalhador com objetivo de atentar contra a dignidade do trabalhador ou mesmo criar um ambiente hostil, intimidativo, humilhante, desestabilizador ou degradante.

A Recomendação n. 200 da OIT, dispóe que " o empregador ou ente público tem o dever positivo de promover açóes no sentido de prevenir e proibir violência e assédio no local de trabalho. Nesse sentido, é elementar a informação e educação no ambiente de trabalho para se manter um clima de confiança e respeito, evitando a estigmatização do trabalhador.

Quanto ao assédio discriminatório por motivo de HIV ou AIDS, fere o fundamental direito do trabalhador ao respeito à sua dignidade e direitos da personalidade, cujo direito de não ser discriminado visa protege-lo no sentido de lhe garantir acesso ou manutenção no emprego. (ALKIMIN, 2013, p. 75) 
A segregação ou estigmatização do trabalhador portador do HIV ou doente de AIDS, gera a exclusão do mesmo da organização do trabalho, deprecia a imagem, fere a autoestima do trabalhador, cuja segregação pode partir do empregador, superior hierárquico ou do colega de trabalho, degradando as condiçóes de trabalho e impedindo um meio ambiente do trabalho sadio e equilibrado para o crescimento pessoal e convívio profissional e social com harmonia e de respeito e consideração ao próximo.

Em termos práticos a segregação do trabalhador portador do HIV ou doente de AIDS pode partir do empregador, tomador dos serviços contratos, dirigente do órgão público contratante da mão de obra, e, deve-se ressaltar, que a segregação também pode partir do colega de trabalho ou de qualquer outro sujeito que componha a organizaçáo do trabalho.

Além disso, a segregação pode se materializar através das seguintes condutas comissivas ou omissivas: atribuição de tarefas ou atividades incompatíveis com a saúde ou condição física do trabalhador; atitudes que impeçam ou dificultem o acesso à promoção ou formação profissional; desvio de função; isolamento noutro local de trabalho; recusa de comunicaçáo e impedimento de manifestação por parte do trabalhador vitimado pela discriminação etc.

\section{d) Divulgaçáo da condiçáo de portador de HIV ou de doente de AIDS (art. 1\%., inciso V)}

$\mathrm{O}$ inciso $\mathrm{V}$ do art. ${ }^{\circ}$. da Lei n. 12.984/2014 também criminaliza a conduta comissiva que implique em divulgação da condição do empregado/trabalhador de portador do vírus HIV ou de doente de AIDS, cuja conduta caracteriza o "animus ofendendi", ferindo a intimidade do trabalhador-vítima do delito- caracterizando ofensa à privacidade do trabalhador e sigilo que deve existir acerca da doença.

A confidencialidade acerca do estado clínico do trabalhador portador do vírus HIV ou doente de AIDS é um dado relativo à esfera da intimidade do trabalhador e que deve ser respeitada pelo empregador, tomador dos serviços ou ente público contratante, inclusive, o sigilo em relação a qualquer informação médica sobre a situação pessoal ou quadro clínico do portador do vírus HIV ou doente de AIDS.

Inclusive a necessidade de confidencialidade motivou o Conselho Federal de Medicina do Brasil a editar a Resolução n. 1359/92 a qual veda os médicos que prestam serviços a empresas de revelarem ao empregador o diagnóstico do empregado ou candidato a emprego, devendo atestar apenas a capacidade de exercer ou náo determinada função (art. 3º, Resolução 1359/1992). Contudo, segundo a mesma Resolução, tratando-se de moléstia infecto-contagiosa, o médico deve comunicar à saúde pública, garantindo-se o anonimato, sob pena de incorrer no delito descrito pelo art. 269 do Código Penal. 
Nesse sentido a Recomendação n. 200 da OIT também prima pela privacidade e sigilo nos casos do candidato, empregado ou trabalhador portador do vírus HIV ou doente de AIDS, determinando que se deve assegurar o efetivo sigilo dos dados pessoais e informaçóes pessoais, inclusive de caráter médico. E no caso de resultados dos testes de HIV, os mesmos devem ser confidenciais, justamente para não prejudicar o acesso a emprego, a manutenção, a garantia de emprego e as oportunidade de promoção.

\subsubsection{Sujeitos: Ativo e Passivo}

De acordo com a Lei penal que criminaliza a discriminação do trabalhador portador do vírus HIV ou doente de AIDS, sujeito ativo da conduta discriminatória capitulada no artigo $1^{\circ}$. e incisos da Lei n. 12.984/2014 será:

a) o empregador quando em curso a relação de emprego, o pretenso empregador ou tomador de serviços no caso de conduta praticada contra o candidato ao emprego ou ao trabalho;

b) o tomador dos serviços no caso da relação de trabalho em sentido amplo, abrangendo o trabalhador avulso, cooperado etc;

c) a unidade concedente na pessoa de seu responsável no caso do contrato de estágio;

d) a administração pública, na pessoa de seu dirigente, no caso de servidor ou funcionário público, que eventualmente seja vítima da conduta discriminatória, incidindo o administrador no tipo penal em comento; e

e) o colega de trabalho ou qualquer outra pessoa que esteja integrada na organização do trabalho.

Portanto, a discriminação do empregado por motivo de portar HIV ou em estado real ou presumido da doença de AIDS, equivale a conduta, ato e comportamento hostil, degradante, humilhante que contamina o meio ambiente do trabalho, cuja conduta pode partir tanto do empregador ou tomador dos serviços, como também de um colega de trabalho ou qualquer outro preposto do empregador.

Na verdade, a prática do ato discriminatório por motivo de HIV/AIDS, seja por parte do empregador, superior hierárquico, tomador dos serviços etc, constitui descumprimento contratual e do dever geral de consideração ao próximo e respeito à dignidade da pessoa humana, logo, impóe a todos o dever de abstenção de qualquer prática discriminatória. Nesse sentido Américo Pla Rodrigues “(...) el cumplimiento de esta obligación, que se descompone en tantas prohibiciones y deberes positivos, no incumbe solo al empleador sino a todas las personas que lo representam”. ( RODRIGUES, 1978, p. 168, apud ALKIMIN, 2013) 
A conduta discriminatória por motivo de HIV/AIDS é uma conduta ilícita, portanto, contrária ao ordenamento jurídico ou ao dever preexistente e que erradia efeitos jurídicos no âmbito trabalhista, civil e penal. Conforme descrição do tipo penal em referência, a conduta discriminatória tem como elemento subjetivo o dolo direto ou o dolo indireto.

O dolo direto significa a intenção deliberada de discriminar e negar emprego ou trabalho, de excluir da organização do trabalho, se segregar da organização do trabalho ou, ainda, de divulgar a condição do trabalhador de portador do vírus HIV ou da doença de AIDS. Já o dolo eventual abrange a consciência e previsibilidade do agente em relação ao resultado danoso que sua conduta discriminatória produzirá, assumindo o sujeito ativo os riscos da sua conduta. Portanto, em ambos os dolos o agente tem consciência da antijuricidade da conduta.

O sujeito passivo da discriminaçáo por motivo de HIV/AIDS, ou seja, a vítima da conduta discriminatória que ridiculariza, hostiliza, denigre e ofende a identidade, personalidade e dignidade do trabalhador, conforme descrição do tipo penal, será o empregado, o trabalhador (estagiário, cooperado, avulso etc), o servidor público ou funcionário público portador do vírus HIV ou doente de AIDS; bem como o candidato ao emprego ou ao trabalho.

Conforme descrição do tipo penal contido na Lei n. 12.984, a vítima ou o sujeito passivo da conduta discriminatória por motivo de HIV/AIDS receberá a tutela penal, nas hipóteses em que os sujeitos ativos acima referidos praticar ou praticarem conduta que implique:

a) negativa de ofertar emprego ou trabalho;

b) exoneração do cargo;

c) demissão do emprego;

d) segregação no ambiente de trabalho; e

e) divulgação da condição de portador do vírus HIV ou da doença de AIDS.

\section{Conclusões}

No Brasil, no âmbito trabalhista, não há norma específica que proteja o trabalhador portador de AIDS/HIV. A lei ora analisada representa indiscutivelmente, um avanço na legislação brasileira, embora a vedação às práticas discriminatórias já estivesse prevista desde 1995, pela Lei 9.029, pois posiciona o Brasil contra a discriminação aos portadores de AIDS/HIV, punindo com multa e prisão, qualquer ato discriminatório seja de forma direta ou indireta. 
É sabido que qualquer atitude de discriminaçấo em atividade laborativa é atentatório à dignidade, que nos portadores de AIDS/HIV torna-se duplamente atingido, não só enquanto trabalhador, como também enquanto pessoa humana. A discriminação e o preconceito sempre acompanharam as pessoas infectadas, desde a descoberta do vírus, e ainda hoje são presenciadas muitas e diversas formas de negaçáo de direitos aos portadores do HIV.

Cediço também que a simples edição de uma legislação específica não provocará de imediato a eliminaçáo de atitudes discriminatórias e preconceituosas contra os portadores da doença, necessitando, obviamente de maior visibilidade da lei.

O desafio agora é tornar a lei visível e efetiva para assegurar o respeito aos cidadãos trabalhadores na defesa do mais preciso dos valores humanos: a dignidade de sua vida, concretizando o objetivo constitucional na construção de uma sociedade mais livre, justa, solidária, sem preconceitos ou discriminação na formação do bem de todos.

\section{Referências}

ALKIMIN, Maria Aparecida. Assédio Moral na Relaçáo de Trabalho. 3. ed. rev. atual. Curitiba: Juruá, 2013.

. Violência na Relaçáo de Trabalho e a Proteção à Personalidade do Trabalhador. Curitiba: Juruá, 2009.

BARROS, Alice Monteiro de. AIDS no local de trabalho: um enfoque de direito internacional e comparado. In Revista Ltr. Vol. 65, março, n. 03, 2001.

BOBBIO, Norberto. A Era dos Direitos. Nova Ed.Tradução de Carlos Nelson Coutinho. Apresentaçáo Celso Lafer. Rio de Janeiro: Elsevier, 2004.

BRASIL. Lei n. 12.984, de 2 de junho de 2014. Define o crime de discriminaçáo dos portadores do vírus da imunodeficiência humana (HIV) e doentes de AIDS. Disponível em: http://www.planalto.gov.br/ccivil_03/_Ato2011-2014/2014/Lei/ L12984.htm. Acesso em: 03 abr 2015.

BRASIL. Constituição (1988). Constituiçáo da República Federativa do Brasil de 1988. Disponível em: http://www.planalto.gov.br/ccivil_03/constituicao/constituicaocompilado.htm. Acesso em: 10 maio 2015.

BRASIL. Lei n. 8112, de 11 de dezembro de 1990. Dispóe sobre o regime jurídico dos servidores públicos civis da União, das autarquias e das fundaçôes públicas federais. Disponível em: http://www.planalto.gov.br/ccivil_03/leis/18112cons.htm. Acesso em: 15 maio 2015.

BRASIL. Lei n. 9029 de 13 de abril de 1995. Proíbe a exigência de atestado de gravidez e de esterilização e outras práticas discriminatórias, para efeitos de admissão e permanência da relação jurídica de trabalho, e dá outras providências. Acesso 5 maio 2015. 
BRITO FILHO, José Cláudio Monteiro.Discriminação no Trabalho. São Paulo: LTr, 2002.

COMAPARTO, Fábio Konder. A afirmaçáo histórica dos Direitos Humanos. 3 ed, rev e ampl. São Paulo: Saraiva, 2003.

CANOTIlHO, J.J. Gomes. Direito Constitucional e Teoria a Constituiçáo. 7. ed. Almedina: Portugal, 2010.

CARVALHO FILHO, José dos Santos. Manual de direito administrativo, Rio de Janeiro: Lumen Juris, 2009.

DI PIETRO, Maria Sylvia Zanella. Direito Administrativo, 23a ed., São Paulo: Atlas, 2010 .

FURTADO, Emmanuel Teófilo. Preconceito no trabalho e a discriminação por idade. São Paulo: LTr, 2004.

FRANÇA, Rubens Limongi de. Aspectos jurídicos da AIDS. In Revista dos Tribunais. Vol. 661 .

JAKUTIS, Paulo. Manual de estudo da discriminação no trabalho: estudos sobre discriminação, assédio moral. São Paulo: LTr, 2006.

MARTINS, Sérgio Pinto. Direitos Fundamentais Trabalhistas. São Paulo: Atlas, 2008.

ORGANIZAÇÃO INTERNACIONAL DO TRABALHO. Convenção n. 111, 1958. Disponível em: http://www.oitbrasil.org.br/node/472. Acesso em: 10 maio 2015.

ORGANIZAÇÃO INTERNACIONAL DO TRABALHO. Recomendação n. 200. CONFERÊNCIA INTERNACIONAL DO TRABALHO, 99., 2010, Genebra. Disponível em: http://www.oitbrasil.org.br/node/277. Acesso em 05 maio 2015.

PEREIRA, Caio Mário. Instituiçóes de Direito Civil. Vol 1. 19ed., rev. e atual. Rio de Janeiro: Forense, 2000.

RAWLS, John. Uma Teoria da Justiça. Brasília: Universidade de Brasília, 1981.

RODRIGUES, Américo Pla. Curso de Derecho Laboral. Montevideo: Acali, 1978.

TELLES JUNIOR, Goffredo. Iniciação na Ciência do Direito. 4a . ed. ver. e atual., São Paulo: Saraiva: 2008. 